\title{
EDUCAÇÃO AMBIENTAL NO SISTEMA PRISIONAL PARANAENSE
}

\section{ENVIRONMENTAL EDUCATION IN THE PARANÁ PRISON SYSTEM}

\author{
CUNICO, M. M. ${ }^{12 *}$; MIGUEL, M. D. ${ }^{3,4}$; SALVADOR, S. F. T. ${ }^{5}$ \\ ${ }^{1}$ Laboratório de Fitoquímica, Departamento de Farmácia, UFPR, Curitiba-PR \\ ${ }^{2}$ SEED-PR/SEJU-PR (CEEBJA Dr. Mário Faraco)*e-mail: miricuni@ gmail.com \\ ${ }^{3}$ Laboratório de Farmacotécnica, Departamento de Farmácia, UFPR, Curitiba-PR \\ ${ }^{4}$ Programa de Pós Graduação em Ciências Farmacêuticas - UFPR \\ ${ }^{5}$ Programa de Pós Graduação em Tecnologia - UTFPR \\ RECEBIDO: 07/07/08 ACEITO:01/08/08
}

\begin{abstract}
RESUMO:
Este artigo relata a aplicação de uma proposta de Ensino de Química voltada para a Educação Ambiental em turma de Ensino Médio de EJA (CEEBJA Dr. Mário Faraco) na Colônia Penal Agrícola do Sistema Penitenciário Paranaense. Tal proposta se valeu de um conjunto de ações em sala de aula com objetivo de esclarecer a interação do homem com a natureza, as formas de apropriação e as conseqüências dessas relações na saúde, no equilíbrio ecológico, além de criar oportunidades para que o indivíduo preso entenda que existem alternativas para sobrevivência a partir da reutilização de garrafas PET. Os resultados confirmaram a viabilidade desta proposta de ensino nos espaços prisionais brasileiros.
\end{abstract}

Palavras-chave: Educação ambiental, ensino de química, sistema prisional.

\begin{abstract}
:
This paper reports the application of a proposal of Chemistry Education, directed to Environmental Education in a group of Secondary Education of EJA (CEEBJA Dr. Mário Faraco), in the Farming Penal Colony of the Paraná Prison System. Such project was validated by a set of action in classroom, which objective was to clarify the interaction of the man with the nature. The forms of appropriation and the consequences of these relations in the health and in the ecological balance (equilibrium) were assimilated, creating opportunities so that the imprisoned student understands that he has alternatives for survival, recycling PET bottles. The results had confirmed the viability of this education project in the Brazilian's prison spaces.
\end{abstract}

Keywords: Environmental education; chemistry teaching; prison system.

\section{INTRODUÇÃO}

A crescente degradação ambiental decorrente do lixo produzido pela civilização moderna tem promovido, em todos os lugares do mundo, uma forma abrangente de ensino que enfoca a Educação Ambiental (EA). Entretanto, o Brasil deixa muito a desejar no que se refere à educação, pois ainda hoje, muitas crianças encontram-se fora da escola, assim como milhões de jovens e adultos.

De acordo com CUNICO (2004), o descaso com os excluídos é mais intenso no sistema penitenciário, já que há carência de pessoal qualificado e de recursos materiais indispensáveis ao resgate da condição humana do indivíduo preso. Diante do exposto e visando manter o aluno preso em condições efetivas de recuperação e ressocialização, foi proposto no CEEBJA Dr. Mário Faraco um Ensino Formal voltado para a EA na Colônia Penal Agrícola (CPA) do Sistema Penitenciário do PR, com o objetivo de esclarecer a interação do homem com a natureza, as formas de apropriação e as conseqüências dessas relações no equilíbrio 
ecológico, além de criar oportunidades para que o indivíduo preso entenda que existem alternativas para sobrevivência a partir da reutilização de garrafas PET (Poliestireno Teraftalato).

\section{A EDUCAÇÃO FORMAL NO SISTEMA PENITENCIÁRIO}

No contexto de uma tecnologia mercadológica, utilitária e capitalista ocorreu a origem dos Estudos de Ciência, Tecnologia e Sociedade (CTS) no decorrer deste texto. Este campo de estudos surgiu como uma área de ensino e investigação sócio-cultural, nos Estados Unidos e Europa nos anos 60 nas bases de uma profunda contra cultura, inserida nesta contra cultura está a Educação Ambiental (WORFMANN; VEIGA-NETO, 2001). A tecnologia tornouse vital à condição da existência humana por fazer parte das estruturas que nos alimentam, nos vestem, nos proporcionam o transporte, a saúde, o entretenimento, o lazer e também propicia o surgimento de entes negativos como a poluição e a degradação do ambiente. $A$ tecnologia media até a relação do ser humano com a morte, se for considerada a indústria de artefatos funerários e a questão do bem-estar ofertado aos enlutados (MACKENZIE; WAJCMAN, 1996).

Na realidade, ciência e a tecnologia não atuam como agentes promotores de nivelamento social, político e/ou econômico. A ciência e a tecnologia estão em geral demasiadamente vinculadas ao benefício imediato de grupos capitalistas, não possuindo uma "relação linear com o bem-estar social, como se tinha feito crer desde o século 19" (LINSISGEN, 1999). Por isso, a atual reestruturação dos estudos CTS gira em torno de ajustar a ciência e a tecnologia aos padrões éticos que já governam outras atividades sociais, isto é, democratizá-las. Portanto, os estudos CTS apresentam-se agora como uma renegociação crítica, com orientações regionais distintas, do papel da tecnologia e da ciência na sociedade ocidental (MITCHAM, 1990). Ajustando-se a esta renegociação, o objetivo da educação em CTS no âmbito educacional e de formação pública é a alfabetização e a escolarização para propiciar a formação de amplos seguimentos sociais. Todos os níveis educativos são apropriados para levar a cabo as mudanças em conteúdos e metodologias, considerando que a orientação dos estudos CTS na educação melhora a criatividade e a compreensão dos conceitos científicos e contribui para desenvolver no estudante uma atividade positiva para a ciência e para a aprendizagem da mesma. Esta postura pode ser aplicada a situação do sistema de ensino nos presídios brasileiros. Para isso, a educação CTS deve compreender os aspectos organizativos, combater os determinismos e alcançar o conteúdo curricular e os aspectos próprios da didática, combatendo os mitos acerca da ciência e enfatizando o papel social da educação de inserir na escola as camadas e grupos excluídos da sociedade. (BAZZO; LINSINGEN; TEIXEIRA, 2003).

Conforme Bourdieu (1996), "não é suficiente enunciar o fato da desigualdade da escola, é necessário descrever os mecanismos objetivos que determinam a eliminação contínua..."

Dos mecanismos objetivos, desenvolvidos no sistema prisional paranaense destacamse os seguintes: A Lei de Execução Penal é explícita quanto à obrigatoriedade dos presídios oportunizarem a seus detentos e aprisionados condições de reeducação, reinserção e ressocialização (MIRABETTE, 1997). Todavia, o indivíduo preso não encontra na prisão uma estrutura de educação que o prepare para a liberdade (LEAL, 1996). Desta forma, os objetivos principais que são a reintegração e a ressocialização do indivíduo preso ficam postergados, sendo raros os casos de presidiários que conseguem suplantar as dificuldades, concluindo um curso secundário, assim como um universitário.

Como ressocializar significa fornecer ao preso um canal pelo qual ele possa reentrar na sociedade, a EA no ensino formal dos espaços prisionais torna-se indispensável, pois oferece oportunidades para o desenvolvimento de habilidades relacionadas à participação política e ao processo de construção da cidadania, contemplando estratégias e ações de 
caráter multidisciplinar e aspectos práticos da questão ambiental, tais como conservação de energia, preservação da saúde e da diversidade biológica, coleta seletiva, reciclagem de materiais, reflorestamento, redução da geração de resíduos, campanhas de conscientização e sensibilização, entre outros (CUNICO, 2004).

\section{PROGRAMA DOS 3 R's}

É muito vasta a possibilidade de reutilização dos materiais contidos no lixo (papel, papelão, metais, trapos, plásticos, vidros), dentre os quais destacam-se: a produção de compósitos, um tipo de adubo orgânico de aplicação na agricultura, em parques e jardins; produção de ração para animais; produção de vapor d' água ou energia elétrica através da incineração dos resíduos sólidos; aproveitamento do gás produzido em aterros sanitários, entre outros (CUNICO, 2004).

A diminuição do acúmulo de lixo a ser despejado nos aterros, a economia de energia e de recursos naturais, os ganhos financeiros oriundos da comercialização de materiais obtidos do lixo, assim como a diminuição da poluição ambiental, também são vantagens evidenciadas em processos de reciclagem (CHERMONT, 1996; VILHENA, 1999; PEREIRA-NETO, 1999; CALDERONI, 2003). Entretanto, torna-se necessário esclarecer que a reciclagem é o resultado de uma série de atividades através de quais materiais que se tornariam lixo ou estão no lixo são desviados, sendo coletados, separados e processados para uso como matéria-prima na manufatura de bens, feitos anteriormente apenas com matéria-prima virgem (OBLADEM et al., 1992). Sendo assim, o programa dos 3 R's (Redução, Reutilização e Reciclagem) revelase como o melhor instrumento para informar, conscientizar e mobilizar a população sobre o problema do lixo atual (FUZARO, 1998; SATO, 1999). É importante ressaltar que a recusa de produtos que se apresentam com desperdício de matéria-prima representa um quarto e importante ' $R$ ', o qual deve ser inserido ao programa 3 R's, visto a pressão do mercado consumidor levar a indústria a uma atitude ambientalmente responsável (FADINI; BARBOSA FADINI, 2001).

\section{PROPOSTA DE ENSINO}

Este projeto enfatizou a importância do meio ambiente e da reutilização de materiais descartáveis no processo de Educação. No trabalho adotado, os conceitos foram em geral, substituídos por uma experiência direta, embora o fato mais importante foi vivenciar o fazer artesanal em grupo, como atividade educativa.

\subsection{METODOLOGIA E ESTRATÉGIAS}

Professores do CEEBJA Dr. Mário Faraco e comunidade escolar participaram ativamente da feitura de "formas", objetos ou produtos, contribuindo e sentindo o ganho de algo importante tanto para a vida educacional, quanto para a vida emotiva $X$ saúde, participativa, ambiental, solidária e multiplicadora. Porém, em todo o trabalho, levou-se em conta a reutilização (o reaproveitamento dos materiais), a economia, a simplicidade, a harmonia, a utilidade dos produtos propostos, a geração de novas tecnologias (pressurização de garrafas PET para emprego em barcos, fios de PET) e a sua aplicação em ações pedagógicas.

Como vantagem principal do método da reutilização dos materiais, considerou-se a formação de uma consciência ambiental para o desenvolvimento de habilidades profissionais e a conseqüente geração de renda. 
Neste projeto foi desenvolvido o tema: "Educação Ambiental", integrando os diferentes conteúdos das diversas disciplinas ofertadas na CPA (Sede e Parque Agrícola), com tópicos do cotidiano do aluno, abordados em aulas teóricas e práticas (oficinas experimentais), as quais foram adaptadas da proposta feita por CUNICO (2004) sobre EA para EJA em Sistemas Prisionais. Os conteúdos desenvolvidos neste trabalho encontram-se inseridos no Quadro 1.

QUADRO 1 - DISTRIBUIÇÃO DOS CONTEÚDOS DESENVOLVIDOS NA COLÔNIA PENAL AGRÍCOLA, PIRAQUARAPR.

\begin{tabular}{|l|l|l|}
\hline \multicolumn{2}{|c|}{ EDUCAÇÃO AMBIENTAL } \\
\hline $\begin{array}{l}\text { Objetivos específicos } \\
\text { O aluno deverá ser capaz } \\
\text { de: }\end{array}$ & \multicolumn{1}{|c|}{ Conteúdos } & \multicolumn{1}{c|}{ Estratégias } \\
\hline $\begin{array}{l}\text { Conhecer o que é lixo, } \\
\text { como é classificado e } \\
\text { descartado. }\end{array}$ & O lixo e o Meio Ambiente & $\begin{array}{l}\text { Exposição oral e com recursos } \\
\text { audiovisuais do conteúdo. (TV } \\
\text { pendrive) }\end{array}$ \\
\hline $\begin{array}{l}\text { Conhecer o impacto } \\
\text { ambiental causado pela } \\
\text { geração e descarte do lixo, } \\
\text { assim como as formas de } \\
\text { amenizar este problema. }\end{array}$ & O programa dos 3 R's. & $\begin{array}{l}\text { Análise do texto Lixo: o mal do } \\
\text { mundo civilizado (TV pendrive) } \\
\text { (www.mma.gov.br). }\end{array}$ \\
\hline $\begin{array}{l}\text { Aplicar soluções para } \\
\text { amenizar o problema } \\
\text { gerado pelos resíduos } \\
\text { sólidos plásticos. }\end{array}$ & $\begin{array}{l}\text { Reutilização de garrafas } \\
\text { PET }\end{array}$ & Oficina experimental. \\
\hline
\end{tabular}

4.2 OFICINAS EXPERIMENTAIS (www.recicloteca.org.br , 2006)

\subsubsection{Cadeira de PET (Fig. 1):}

FIGURA 1 - CADEIRA DE PET

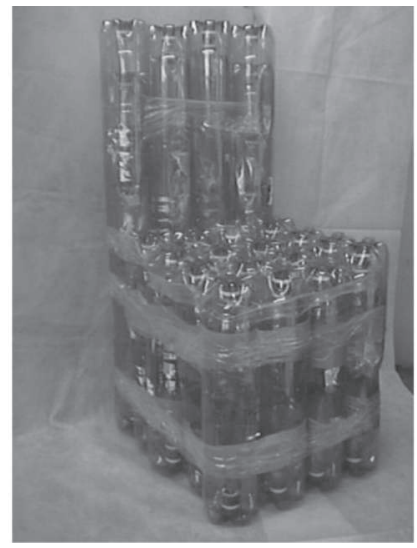

Material necessário:

- 78 garrafas PET de $2 \mathrm{~L}$.

- 1 tesoura.

- 1 rolo de fita adesiva.

FONTE: FOTO DE CUNICO (2006) 
Procedimento:

1. Lavar as garrafas com água sanitária e detergente, retirando os seus rótulos, em seguida enxaguá-las (pelo menos 5 vezes) e secá-las bem;

2. Dividir a garrafa em 3 partes imaginárias, cortando-a com uma tesoura no primeiro terço superior;

3. Colocar a parte menor dentro da parte maior obtida na etapa anterior, empurrando até que o gargalo da parte menor encoste-se no fundo da parte maior;

4. Fazer 32 peças seguindo as etapas 1 a 3;

5. Colocar 1 garrafa inteira dentro de cada peça obtida na etapa 4;

6. Dividir 32 garrafas em 3 partes imaginárias, cortando-as com uma tesoura no primeiro terço superior;

7. Colocar a parte menor dentro da parte maior obtida na etapa 6 , empurrando até que o gargalo da parte menor encoste-se no fundo da parte maior;

8. Encaixar a peça obtida na etapa 7 em cada peça obtida na etapa 6;

9. Juntar as peças anteriores aos pares utilizando fita adesiva;

10. Juntar aos pares, com fita adesiva, as peças duplas da etapa anterior e novamente juntar aos pares as peças anteriores com fita adesiva, para formar a base da cadeira;

11. Montar 4 peças da etapa 9 para fazer o encosto da cadeira;

12. Montar 4 a 5 peças da etapa 4 colocando-as uma encima da outra;

13. Juntar com fita adesiva o encosto com a base da cadeira.

Pode-se forrar o assento da cadeira com papelão e espuma, assim como encapála com tecido ou outro tipo de material reaproveitável.

É importante ressaltar que esta oficina experimental se deve ao espírito inventivo e ao pioneirismo do Prof. Sebastião Feijó, criador da técnica das peças de resistência com garrafas PET.

\subsubsection{Vassoura de PET (Fig. 2):}

FIGURA 2 - VASSOURA DE GARRAFAS PET

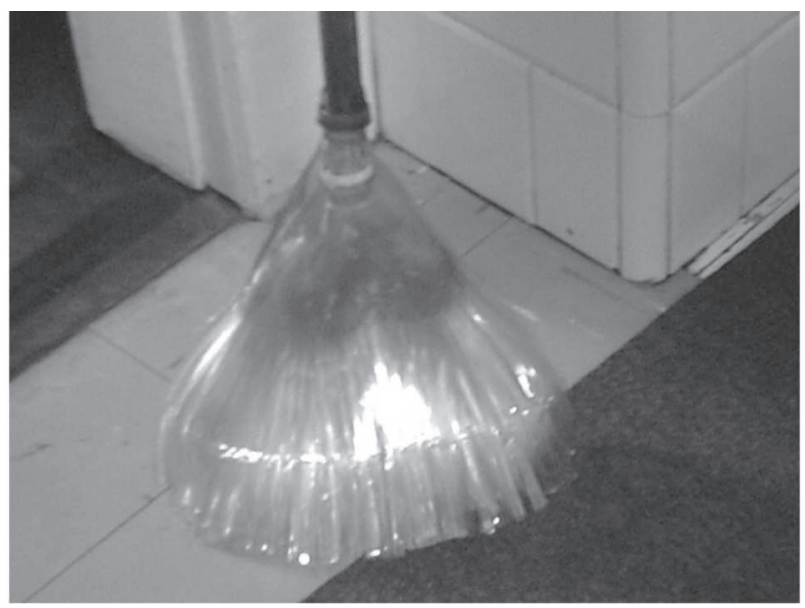

Material necessário:

- 19 garrafas PET de $2 \mathrm{~L}$.

- 1 cabo de vassoura

- 1 tesoura

- 1 pedaço de arame

- 2 pregos

- 1 martelo

FONTE: FOTO DE CUNICO (2006) 
Procedimento:

1. Lavar as garrafas com água sanitária e detergente retirando os rótulos das mesmas, em seguida enxaguá-las e secá-las.

2. Cortar o fundo das garrafas com uma tesoura,

3. Fazer tiras de $0,5 \mathrm{~cm}$ até a parte arredondada nas 18 peças obtidas na etapa anterior,

4. Retirar, com uma tesoura, o gargalo das 17 peças obtidas na etapa anterior encaixando cada uma das 17 peças sem gargalo por cima da peça que contém o gargalo,

5. Cortar a parte de cima de outra garrafa e encaixá-la por cima da base da vassoura obtida na etapa anterior,

6. Em seguida fazer 2 furos na peça obtida na etapa anterior, atravessar o arame por todas as camadas de PET, puxar o arame até o lado oposto e arrematar as pontas do arame (torcer),

7. Fixar com 2 pregos o cabo da vassoura encaixada no gargalo da peça obtida na etapa anterior.

4.2.3 Embalagem para bombons feita a partir de garrafa PET (Fig. 3):

FIGURA 3 - EMBALAGEM DE GARRAFAS

PET PARA BOMBONS

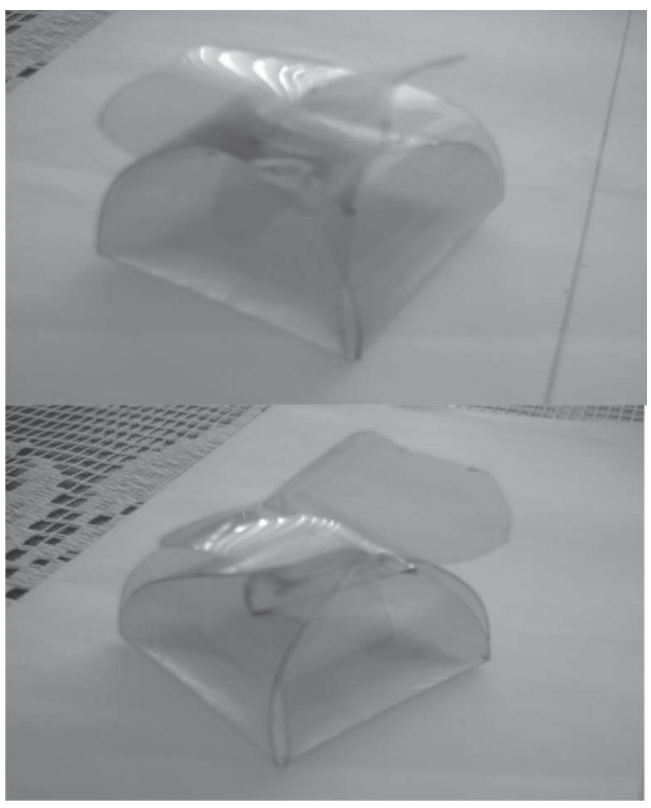

Material necessário:

- 1 garrafa PET de $2 \mathrm{~L}$

- 1 tesoura

- 1 molde

FONTE: FOTO DE CUNICO (2006).

Procedimento:

1. Lavar a garrafa PET com água sanitária e detergente, em seguida enxaguá-las e secá-las. 
2. Retirar o rótulo da garrafa PET;

3. Cortar as extremidades da garrafa PET com uma tesoura;

4. Recortar a embalagem com uma tesoura após sobrepor o molde da embalagem na tira retangular de PET obtida na etapa anterior. * A partir de 1 garrafa de PET (2L) pode-se obter 2 embalagens para bombons.

\section{CONSIDERAÇÕES FINAIS}

Esta proposta favoreceu ações compartilhadas entre direção, funcionários e professores do CEEBJA Dr. Mário Faraco e da CPA. Porém esta mudança necessitou da adoção de uma nova postura diante dos valores vigentes, visando, sobretudo a preservação ambiental e uma crescente humanização. Além disso, foi necessário fazer uma abordagem cuidadosa sobre a reutilização de garrafas $\mathrm{PET}$, para que os alunos presos não a confundissem com um discurso mascarado de "ecologicamente correto" tampouco com ecologismo, onde há uma preocupação exacerbada com a natureza e não com os problemas sócio-econômicos de habitantes de determinadas comunidades, tais como o lixo e as sub-condições de vida de diversas pessoas que subsistem do mesmo (CUNICO, 2004; RIBEIRO, 2006).

De acordo com LORENZE (2003), educar promove transformações no sentido de tornar o cidadão apto a agir, a mudar, a criar, inovar, criticar, a cooperar, a recomeçar ou voltar atrás se for preciso, mas, sobretudo, a ter esperança e comprometimento com o futuro, por meio do conhecimento.

Os resultados obtidos neste trabalho confirmaram a viabilidade da aplicação desta proposta de ensino nos espaços prisionais brasileiros.

\section{REFERÊNCIAS}

BOUDIEEU, Pierre. L'école conserveince. Les inégalitès devant l'école ET La culture. Publicado originalmente in Rvue Française de Sociologie. Paris. v.7, n.3, p. 325-347, 1966.

CALDERONI, S. Os bilhões perdidos no lixo. São Paulo: Humanitas/FFLCH/USP, 2003.

CHERMONT, L.S.; MOTA, R.S. Aspectos econômicos da Gestão Integrada de resíduos sólidos. Rio de Janeiro: IPA, 1996.

CUNICO, M. M. Lixo e meio ambiente: uma proposta para o ensino de química e de geografia na educação de jovens e adultos em espaços prisionais. 2004, 94 f. Monografia (Especialização em Educação de Jovens e Adultos) Faculdades Integradas Curitiba, CuritibaPR.

FUZARO, J.A. Coleta Seletiva para prefeituras. São Paulo: SMA/CETESB, 1998.

FADINI, P. S.; BARBOSA FADINI, A. A. Lixo: desafios e compromissos. Cadernos Temáticos de Química Nova na Escola, ed. especial, maio, 2001.

LEAL, C. B. O crepúsculo de uma era. Revista do Conselho Nacional de Política Criminal e Penitenciária Brasília: Ministério da Justiça. v.8, n.1, p.33-39, jul./dez.1996. 
LINSIGEN, I. A transposição didática e o ensino de engenharia. Anais do COBENGE 99, Natal-RN, 1999, p. 677-684.

Lixo: o mal do mundo civilizado. Manual de educação para o consumo sustentável. p.113130. Disponível em: http://mma.gov.br acessado em 03 de março de 2007 ou http:// portal.mec.gov.br/secad/arquivos/pdf/educacao ambienta/consumos.pdf I acessado em 03 de março de 2007.

LORENZI, G. M. A. C. EDUCAÇÃO AMBIENTAL: EDUCAR OU INFORMAR? Visão Acadêmica, v. 4, n. 2, p. 129-136, Jul.- Dez./2003.

MACKENZIE, Donald; WAJCMAN, Judy. Introdutory essay and general issues. In: MACKENZIE, Donald; WAJCMAN, Judy. The social shaping of technology. Buckingham, Philadelphia: Open University Press, 1996.

MIRABETTE, J. F. Execução penal: comentários à Lei no 7210, de 11-7-84. 8ªed. São Paulo: Atlas, 1997.

MITCHAM, C. Em busca de una nueva relación entre Ciencia, Tecnologia Y Sociedad. In: MEDINA, M.; SANMARTIN, J. (Orgs.). Ciencia, tecnología y estudos interdisciplinares em la universidad: la educacíón y em la gestión pública. Barcelona. Anthropos, 1990.

OBLADEN, N. O.; CHACOLOWISKI Jr. F.; RUCINSKI E. J. Reciclagem de resíduos urbanos na região metropolitana de Curitiba. 6. ed. Curitiba: PUC, 1992.

PEREIRA-NETO, J.T. Quanto vale o nosso lixo. Projeto Verde Vale. Viçosa: Ação e Promoção, 1999.

Recicloteca. Disponível em: http://www.recicloteca.org.br Acessado em 03 de março de 2007.

RIBEIRO, V. Quando a educação ambiental não passa de um lixo! UNIrevista. v. 2, n.2, 2006. Disponível em http://www.unirevista.unisinos.br/_pdf/UNIrev_Ribeiro.pdf Acessado em 03 de março de 2007.

VILHENA, A. Guia da Coleta Seletiva de Lixo. São Paulo: CEMPRE, 1999.

WORFMANN, M. Lúcia; VEIGA-NETO, Alfredo. Introdução. In: ESTUDOS culturais da ciência e educação. Belo Horizonte: Autêntica, 2001. 